https://doi.org/10.34179/revisem.v6i1.14757

\title{
IMPACTO DO OUTLIER NA MÉDIA E NA MEDIANA: REFLEXÕES GERADAS POR PROFESSORES
}

\section{IMPACT OF THE OUTLIER IN THE MEAN AND MEDIAN LINE: TEACHERS' REFLECTIONS}

\author{
Angélica da Fontoura Garcia Silva \\ Universidade Anhanguera de São Paulo - UNIAN \\ angelicafontoura@anhanguera.com \\ Tiago Augusto dos Santos Alves \\ Universidade Anhanguera de São Paulo - UNIAN \\ tiago.alves.math@gmail.com \\ Marta Élid Amorim \\ Universidade Federal de Sergipe - UFS \\ martaelid@mat.ufs.br
}

\section{Resumo}

Este artigo apresenta uma pesquisa desenvolvida em um contexto de formação continuada, vivenciado por professores que lecionam Matemática para os Anos Finais do Ensino Fundamental e Médio. Trata-se de um estudo de natureza qualitativa por meio do qual procura-se interpretar os conhecimentos profissionais explicitados por um grupo de 12 professores a partir de sua participação em uma das atividades do processo formativo. Os dados coletados são analisados a partir de estudos que discutem os conhecimentos necessários para o ensino da Matemática e refletem sobre a prática docente. A interpretação dos diálogos dos participantes permite inferir a ampliação do nível de letramento concernente às Medidas de Tendência Central (MTC) e o desenvolvimento do conhecimento comum e especializado do conteúdo, sobretudo a partir da reflexão sobre as MTC serem ou não afetadas pelos outliers e sobre sua utilização ou não para a composição dos dados.

Palavras-chave: Conhecimento profissional docente. Reflexão sobre a prática. Ensino de Medidas de Tendência Central. Outlier.

\begin{abstract}
This paper presents research developed in a context of continuing education, experienced by teachers who teach mathematics in the final years of elementary and high school. It is a qualitative study through which it seeks to interpret the professional knowledge made explicit by a group of 12 teachers from their participation in one of the activities of their qualification process. The data collected are analysed based on studies that discuss the knowledge necessary for teaching mathematics and reflect upon teaching practice. The interpretation of the participants' dialogues allows us to infer the increase in the level of literacy concerning the measures of central tendency
\end{abstract}


(MCT) and the development of common and specialised content knowledge, especially from the reflection on whether the MCT are affected by outliers and whether they should be used to compose the data.

Keywords: Professional teaching knowledge. Reflection on practice. Teaching of measure of central tendency. Outlier.

\section{INTRODUÇÃO}

Este artigo apresenta resultados da investigação de Alves (2016). Com ele, temos o propósito de analisar as reflexões realizadas e os conhecimentos profissionais explicitados por 12 professores em uma sessão de formação na qual se analisou uma situação prática para promover a discussão dos docentes sobre Medidas de Tendência Central (MTC) e seu ensino.

Esta pesquisa integra um conjunto de investigações sobre conhecimentos profissionais e práticas de ensino de professores que lecionam Matemática para a Educação Básica ao trabalhar com Probabilidade e Estatística. Este trabalho foi desenvolvido no Programa de Pós-Graduação em Educação Matemática da Universidade Anhanguera de São Paulo pelo Grupo de Formação de Professores e foi financiado pela Coordenação de Aperfeiçoamento de Pessoal de Nível Superior (Capes).

A escolha do tema Ensino de Estatística no contexto de um processo de formação continuada apoia-se em estudos como os de Gea et al. (2016), que discutem a relevância da realização de pesquisas com esse tópico. Além disso, atualmente, os professores brasileiros têm como tarefa a implementação de um currículo fundamentado na Base Nacional Comum Curricular (BNCC). Esse documento propõe a inclusão de uma unidade temática obrigatória, denominada "Probabilidade e Estatística", e indica que é esperado que os estudantes, ao final da Educação Básica,

[...] saibam planejar e construir relatórios de pesquisas estatísticas descritivas, incluindo medidas de tendência central e construção de tabelas e diversos tipos de gráfico. Esse planejamento inclui a definição de questões relevantes e da população a ser pesquisada, a decisão sobre a necessidade ou não de usar amostra e, quando for o caso, a seleção de seus elementos por meio de uma adequada técnica de amostragem. (BRASIL, 2018, p. 275)

Nesse contexto, os professores de Matemática necessitam estar preparados para planejar o ensino para que seus alunos desenvolvam tais habilidades. Todavia, estudos recentes - como os de Amorim, Pietropaolo e Garcia Silva (2020), Macedo (2016), Rodrigues e Ponte (2020) e Sera (2016) - mostram limitações do conhecimento profissional docente para o ensino da Estatística. Assim, propor uma investigação sobre as 
reflexões geradas e os conhecimentos explicitados por profissionais que ensinam Estatística a partir de um processo formativo nos parece relevante.

\section{FUNDAMENTAÇÃO TEÓRICA}

Expomos aqui os referenciais que nos serviram de apoio para o planejamento da seção de análise dos dados coletados. Selecionamos estudos sobre Letramento Estatístico, Conhecimento Profissional Docente e Reflexão sobre a Prática.

Assim como Gal (2004), consideramos a relação direta que há entre o desenvolvimento do Letramento Estatístico e a competência necessária a todo o cidadão para avaliar e interpretar com criticidade informações estatísticas. Esse autor propõe uma ação conjunta de dois grupos de componentes — os elementos de conhecimento e os elementos deposicionais —, que leva a esse letramento. Para Gal (2004), o cidadão será considerado estatisticamente letrado se possuir uma base de conhecimentos que lhe permita organizar e comunicar informações coletadas em diferentes contextos, além de argumentar sobre os motivos que o levaram a chegar a suas conclusões.

No âmbito da formação de professores, buscamos suporte nos estudos de Ball, Thames e Phelps (2008) sobre a base de conhecimentos necessária ao ensino e em Zeichner (2008). Esses autores discutem a reflexão coletiva na prática.

Ball, Thames e Phelps (2008), apoiados em Shulman (1986), identificam uma base de conhecimentos necessários para o ensino da Matemática. Os autores reconhecem estas seis categorias: conhecimento comum do conteúdo; conhecimento do horizonte do conteúdo; conhecimento especializado do conteúdo; conhecimento do conteúdo e dos estudantes; conhecimento do conteúdo e do ensino e, finalmente, conhecimento curricular do conteúdo. Neste estudo, atemo-nos ao conhecimento comum do conteúdo e ao conhecimento especializado do conteúdo, os quais serão descritos a seguir.

Para Ball, Thames e Phelps (2008), o conhecimento comum do conteúdo se refere ao conhecimento que todo cidadão deveria ter para exercer sua atividade profissional. Essa generalidade não significa que ele seja superficial, tampouco indica que as estruturas organizacionais desse conhecimento sejam sempre necessárias para ensinar. Para o professor, esse conhecimento permite a utilização correta de termos, representações e notações, assim como possibilita identificar incorreções ou inadequações em materiais didáticos ou em produções dos alunos, por exemplo. 
O conhecimento especializado do conteúdo diz respeito ao saber matemático utilizado exclusivamente na docência. A despeito de ser específico do ensino, não faz parte do rol de conteúdos a serem ensinados. Segundo Ball, Thames e Phelps (2008), está relacionado à capacidade de compreender quais seriam as possíveis causas de erros dos alunos e apresentar a eles explicações, exemplos diversificados e respostas precisas do ponto de vista da Matemática.

Essa categorização foi utilizada tanto para planejar o processo formativo como para analisar os dados coletados para este estudo. Além disso, apoiamo-nos na obra de Zeichner (1993), que discute a construção de teorias, pelos professores, a partir de suas práticas e de suas reflexões sobre as práticas realizadas de forma coletiva. Zeichner (1993) afirma que a prática docente envolve uma multiplicidade de teorias. Para o autor, os docentes "[...] estão sempre a teorizar, à medida que são confrontados com vários problemas pedagógicos, tais como a diferença entre suas expectativas e os resultados." (ZEICHNER, 1993, p. 21). Nesse contexto, o autor defende a necessidade de constantes reflexões sobre a prática, especialmente as realizadas coletivamente.

Diante do exposto, buscamos aqui analisar discussões ocorridas em uma das sessões de formação. Procuramos, especificamente, indícios de reflexões coletivas a respeito das ideias ligadas às Medidas de Tendência Central (MTC).

\section{METODOLOGIA}

Esta pesquisa, de natureza qualitativa, foi aprovada pelo Comitê de Ética em Pesquisa vinculado à Comissão Nacional de Ética em Pesquisa (CEP/CONEP), sob o número 982.198, e desenvolvida âmbito do Projeto Observatório da Educação ${ }^{1}$. O foco deste era a formação de professores e pesquisa; para tanto, foi constituído um grupo com professores e pesquisadores da área da Educação Matemática. O referido projeto tinha como meta constituir grupos colaborativos que vislumbrassem estudar e compreender aspectos ligados à prática docente e ao desenvolvimento profissional de seus participantes.

A pesquisa exposta neste artigo foi realizada em uma das sessões de formação desenvolvida no processo formativo. Ela contou com a participação de 12 professores que

\footnotetext{
${ }^{1}$ O Projeto Observatório da Educação. Auxílio no 1052/2013 D.O. 30/07/2013: Investigações sobre o Processo de Ensino e de Aprendizagem de Conceitos concernentes à Probabilidade e Estatística. Coordenado pelo Professor Doutor Ruy César Pietropaolo.
}

ReviSeM, Ano 2021, No. 1, p. 107-123 
lecionavam no Ensino Fundamental e Médio da Educação Básica em escolas públicas de São Paulo e 4 pesquisadores ( 2 doutores e 2 mestrandos do Programa). Os professores foram referenciados pelas letras A a L com a finalidade de garantir o anonimato e atuavam como docentes, em média, há 15 anos, com desvio-padrão de valor igual a 7. Da mesma forma, designamos os pesquisadores que faziam parte do Programa de Pós-graduação mencionado como $1,2,3$ e 4 .

A coleta dos dados aqui analisados ocorreu na primeira sessão de formação. Nela, houve o desenvolvimento da primeira Atividade Prática $^{2}$, a qual teve como objetivo favorecer a reflexão e a discussão entre os professores investigados acerca dos significados, das características e da importância das MTC para a análise e a representação de um conjunto de dados. A princípio, foi apresentado aos professores um recipiente transparente completamente cheio de confeitos (confetes de chocolate).

Figura 1 - Primeiro recipiente transparente completamente cheio de confetes de chocolate

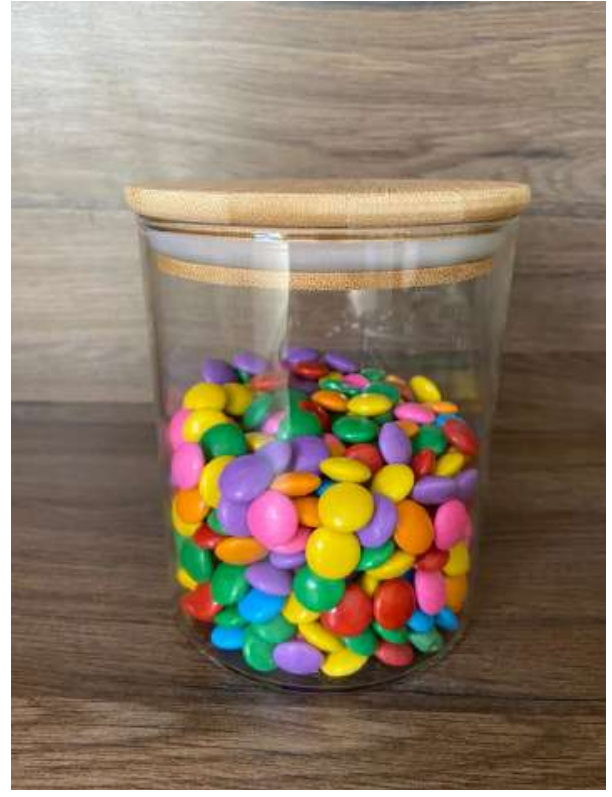

Fonte: Acervo da pesquisa

Na sequência, os professores registraram em um papel a quantidade de doces que cada um deles acreditava haver no referido recipiente. Depois disso, realizamos uma segunda coleta de estimativas, mas, desta vez, despejamos, à vista de todos, os confeitos em uma tigela retangular.

\footnotetext{
${ }^{2}$ Esta atividade foi inspirada na encontrada em Healy e Hoyles (1993), que envolve a estimativa de quantidades.
} 
Figura 2 - Segundo recipiente transparente retangular com confetes de chocolate

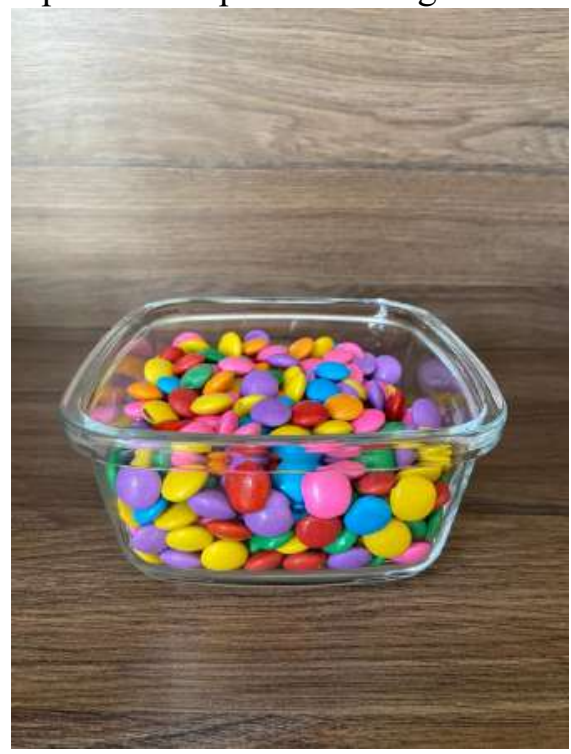

Fonte: Acervo da pesquisa

Depois das discussões e reflexões sobre as duas coletas, houve uma terceira coleta de estimativas. Essa proposta foi realizada por sugestão de um dos participantes, que argumentou que as reflexões do grupo lhe incentivaram a mudar seu palpite sobre a quantidade existente.

Nesse contexto, optamos por realizar uma nova coleta de estimativas. Dessa forma, despejamos, à vista de todos, os confeitos em uma bandeja retangular, maior que a tigela utilizada anteriormente, de modo que os doces ficaram bem espalhados no recipiente, e solicitamos aos professores que apontassem uma terceira estimativa.

Figura 3 - Terceiro recipiente transparente retangular com confetes de chocolate

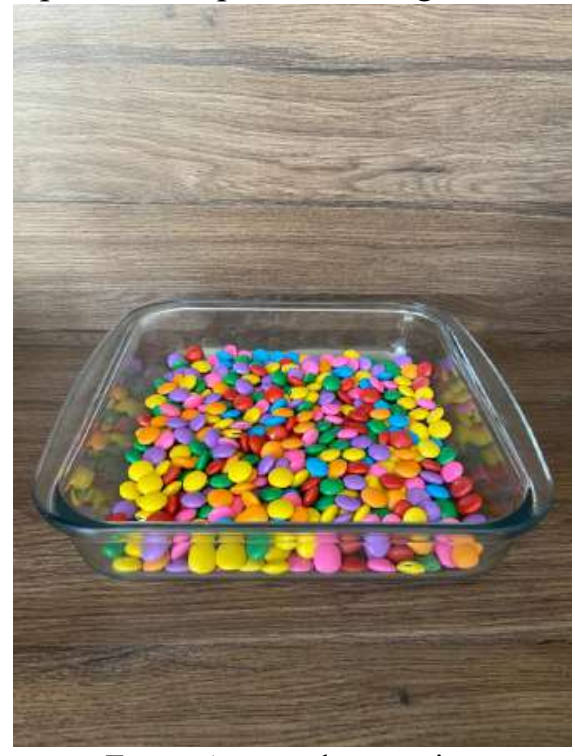

Fonte: Acervo da pesquisa 
Tínhamos o intuito de verificar até que ponto a nova estimativa poderia influenciar a decisão adotada pelos participantes, uma vez que julgamos que o novo recipiente possibilitaria uma diferente visualização da quantidade de doces. Recolhemos as estimativas da quantidade de confeitos a partir da visualização nos três potes e fizemos as discussões tendo em vista tais registros.

\section{DISCUSSÃO E ANÁLISE DOS DADOS}

A partir da exposição do pote transparente completamente cheio de confetes de chocolate aos participantes - professores e pesquisadores —, solicitamos que cada um deles estimasse uma quantidade e a registrasse em uma folha de papel. Nesse momento, o Pesquisador 1 sugeriu uma estimativa de valor - intencionalmente, um número bem elevado. Isso ocorreu com o propósito de que houvesse, no mínimo, um número discrepante entre os valores apresentados pelo grupo, de modo que tal aspecto pudesse ser objeto de discussão e reflexão entre os professores.

A princípio, foram escritos na lousa (Quadro 1) os dados da primeira coleta, redigidos à vista de todos os presentes e dispostos na sequência em que foram apresentados.

\begin{tabular}{|} 
Quadro 1 - Registros da $1^{a}$ coleta de dados da Atividade Prática n. ${ }^{\circ} 1$ \\
$73,460,698,750,270,235,169,314,2500,180,3300,256,239$ \\
\hline
\end{tabular}

Fonte: Acervo da pesquisa

A fim de contextualizar a Atividade Prática e favorecer um ambiente de discussão e reflexão entre os docentes participantes do curso de formação continuada, o Pesquisador 1 apresentou o seguinte contexto: "Considerando as estimativas apresentadas, queremos que os senhores apresentem um valor, ou uma forma de determinar um valor, que melhor represente a opinião do grupo da quantidade de doces contidos no pote." Diante disso, o Professor I sugeriu que, como ponto de partida, calculássemos a média dos valores a partir da divisão da soma deles por 13, que era a quantidade de estimativas registradas na lousa.

Entretanto, os professores E e K levantaram a discussão acerca de o número 73 ser destoante dos demais dados. Da mesma forma, outros participantes também comentaram que os números 2.500 e 3.300 também eram discrepantes diante dos outros valores. Com essas reflexões, o Pesquisador 3 questionou os professores acerca de sugestões para tais valores. O Professor I apontou que tais números poderiam ser excluídos para, na sequência, 
calcularmos a média dos demais valores. Entretanto, o Professor D contrapôs seu argumento dizendo que, caso fizéssemos o que ele havia proposto, não teríamos mais a média dos valores.

Nessa perspectiva, o Pesquisador 2 levantou uma hipótese que favoreceu a reflexão entre os professores no sentido de buscar outros meios para contornar tal limitação, como utilizar a mediana. Tal discussão pode ser observada no episódio a seguir (Quadro 2):

Quadro 2 - Episódio 1

Pesquisador 2: Mas, nesse caso, você poderia descartar o valor correto.
Professor I: Poderia. É um risco, não é?
Pesquisador 2: Você [dirigindo-se ao Professor D] quer dizer que deixaria de
ser a opinião do grupo?
Professor D: Não seria mais a média do grupo.
Professor G: Isso que eu ia falar.
Professor D: E se for a mediana?
Professor G: Mediana? Eu acho que é certo tirar a média de todos os valores.

Fonte: Acervo da pesquisa

Percebemos pelas reflexões dos professores que surgiu o conflito acerca de qual medida poderia representar as estimativas dos participantes. Os professores precisavam apontar um número que realmente representasse as apostas do grupo, mas alguns deles, como os professores D e I, disseram que a média seria afetada por valores extremos. Como uma possível solução, o Professor D, então, sugeriu que fosse utilizada a mediana dos valores para representar o grupo. Entretanto, o Professor G não concordou e se posicionou a favor de que fosse feita a média de todos os valores, sem exclusões.

Diante dessas reflexões, foram realizados os cálculos da média do conjunto de dados. Primeiro, foram considerados todos os valores. Num segundo momento, foram excluídos os números 73, 2.500 e 3.300. Obtivemos, respectivamente, as médias 726,46 e 357,1. Além disso, o Professor I comentou que a sequência de dados era amodal, ou seja, afirmou não havia moda entre os valores.

Realizamos uma segunda coleta de estimativas. Mas, dessa vez, despejamos, à vista de todos, os confeitos em uma tigela retangular. Na sequência, foram escritos na lousa, mantendo-se os registros anteriores, os valores correspondentes à segunda coleta de estimativas dos professores, e, novamente, o Pesquisador 2 indicou um número discrepante dos demais. Essas estimativas encontram-se no Quadro 3. 
Quadro 3 - Registros da $2^{\mathrm{a}}$ coleta de dados da Atividade Prática n. ${ }^{\circ} 1$

$250,2000,320,245,350,256,320,180,950,85,485,598,290$

Fonte: Acervo da pesquisa

Diante das novas estimativas, o Pesquisador 3 questionou os professores acerca do posicionamento deles diante dos novos valores e perguntou o que poderia ser feito para que determinassem um número que representasse as estimativas do grupo. Dessa vez, os professores $\mathrm{C}$ e I citaram que o número 2.000 era discrepante quando comparado aos demais e falaram que seria adequado que ele fosse desconsiderado para o cálculo da média. Entretanto, o Professor G novamente se posicionou contra tal prática, fazendo a seguinte colocação: "Você está trabalhando com o grupo. Então, você tem que trabalhar com o que você tem do grupo." A fim de coordenar a discussão, o Pesquisador 2 informou que as duas maneiras seriam feitas para que, depois, o grupo analisasse os valores.

Como foram excluídos três valores em um dos cálculos da média da primeira coleta de estimativas, o grupo de professores decidiu adotar o mesmo critério para o cálculo da média do segundo conjunto de estimativas ao desconsiderar valores discrepantes, ou seja, também deveriam ser descartados 3 números desse conjunto. Por conseguinte, eles citaram que os valores 85,950 e 2.000 seriam os omitidos na referida situação. Assim, para a média da segunda coleta de estimativas, o resultado foi 486,84 e, ao desconsiderar os números descartados, foi obtido o valor médio de 329,4.

Além disso, o Professor A comentou que, nessa segunda coleta de estimativas, a moda, cujo valor era 320, poderia ser utilizada. É interessante ressaltar que, ao recorrermos ao Questionário Inicial - na pergunta que solicitava a escolha de uma das empresas para trabalhar, tendo apenas as informações dos salários médios, medianos e modais -, o docente havia optado pela companhia que apresentava o maior valor modal e havia justificado sua decisão apontando que isso indicava maior incidência do salário referente a tal medida. Entretanto, nesta Atividade Prática, o referido professor tinha acesso a todas as estimativas e, apesar disso, optou novamente pela moda. Isso nos sugere a prioridade que ele atribuía a essa medida diante da média e da mediana ${ }^{3}$, momento em que ainda persistiam algumas limitações conceituais dos participantes acerca da moda.

\footnotetext{
${ }^{3}$ Esse tópico foi tratado com maior profundidade em outra sessão, mas, devido à falta de espaço em um único artigo, optamos por apresentar esse episódio em outra publicação.
} 
Como na sequência anterior fora citado que a mediana seria uma opção, o Pesquisador 1 a retomou sugerindo aos participantes da pesquisa que fossem calculadas as medianas dos dois conjuntos de estimativas. Entretanto, o Professor A questionou se tal medida deveria ser calculada a partir de todos os dados ou se deveriam, assim como na média, ser descartados os números discrepantes.

Diante desse questionamento, o Pesquisador 1 informou que essa decisão estaria a cargo deles. Assim sendo, caberia aos participantes escolherem os meios que seriam utilizados. Se eles optassem por seguir os mesmos moldes aplicados nos cálculos das médias - primeiro considerando todos os dados e, num segundo momento, descartando três valores discrepantes —, assim seria feito. O Pesquisador 2 acrescentou: "Quando você calcula a média, está utilizando uma fórmula matemática. Entretanto, para a tomada de decisão, baseando-se na Estatística, você levará em conta outros fatores."

O Pesquisador 3, então, questionou os professores acerca de qual procedimento usariam para o cálculo da mediana. O referido mediador destacou esse aspecto por conta de o Questionário Inicial ter-nos apontado limitações acerca dos procedimentos de obtenção da mediana; diante da reflexão em grupo, estas poderiam ser superadas. Além disso, a discussão em grupo, provavelmente, contribuiria com o desenvolvimento do conhecimento comum do conteúdo e com o aprimoramento do nível de Letramento Estatístico dos participantes desta investigação.

O Professor $\mathrm{H}$ disse que bastaria organizar os dados em forma de rol e identificar o valor central. Já o Professor I comentou que se tratava de uma sequência de dados com quantidade ímpar de elementos, o que favorecia obter a mediana do conjunto de modo imediato. Contudo, o referido docente acrescentou que, para o cálculo da mediana de um conjunto com uma quantidade par de elementos, os dois valores localizados no centro do rol teriam de ser somados, e o resultado obtido deveria ser dividido por dois.

Assim, calcularam as medianas. Para a primeira sequência de dados, foi obtido o número 270 e, desconsiderando os valores 73, 2.500 e 3.300, o resultado foi 263. Em relação à segunda sequência, os números indicados foram $320 \mathrm{e}$, ao desconsiderar os dados 85,950 e 2.000, a mediana igual a 305.

Entretanto, o Professor I disse que, apesar de a mediana de valor 320 ter coincidido com a moda, ainda não era um bom número para representar o conjunto. Além disso, ele sugeriu que os 2 conjuntos de dados poderiam ser considerados ao mesmo tempo e, 
portanto, poderia ser calculada a média em relação a todas as estimativas, desconsiderando só os 6 valores discrepantes.

Cabe ressaltar que a medida solicitada pelo professor foi calculada, obtendo-se o número 343,25. Apesar de ser bem próximo do valor da mediana, o Professor I demonstrou a convicção de que a média seria a mais adequada para representar o conjunto de dados. Essa percepção pode estar relacionada ao Elemento Disposicional do modelo de Letramento Estatístico proposto por Gal (2004), chamado Crenças, o qual necessita de tempo para se desenvolver e resiste a mudanças.

A partir desse valor, o Pesquisador 3 perguntou se todos os participantes concordavam se esse número poderia representar o grupo. Dessa questão, surgiram as reflexões expostas no Quadro 4 (Episódio 2).

Quadro 4-Episódio 2

Professor K: Eu descartaria a unidade, a parte decimal, e arredondaria pra
340. Fica mais lógico.
Professor E: Eu prefiro 350.
Professor I: O que acontece numa amostragem? Quando você pega um
número e lança um número totalmente fora, você vai puxar todo o conjunto,
média, mediana, para o lado dele. Vai convergir tudo na sua direção. Então,
se você eliminar os valores discrepantes, a ideia é que a coisa fique mais
centralizada.

Fonte: Acervo da pesquisa

Como o Professor I comentou que a mediana também seria influenciada, o Pesquisador 3 acrescentou: "Mas a mediana também é influenciada? Quando eu tenho um valor discrepante, tanto a média quanto a mediana e a moda são influenciadas?" Então, o Professor I, percebeu seu equívoco, respondeu ao questionamento e acrescentou outras reflexões: “A mediana não. A moda é o que mais aparece. E a média não vai ter sentido nenhum, porque a média não vai representar nada. Se eu tiver um valor muito grande, no caso 3.300, na minha opinião, está absurdo aquilo ali, vai puxar para o lado do 3.300." Reconhecendo uma característica importante da mediana, o Professor K a enfatizou perante o grupo: "Mas a mediana não é influenciada, porque esses valores absurdos estão nos extremos."

Dando continuidade às discussões e considerando que o número 320 representava a mediana e a moda da segunda coleta de dados, o Pesquisador 1 apresentou o seguinte questionamento aos participantes do curso: "Vocês perceberam que, considerando todas as estimativas lançadas na lousa, nós temos 3 modas? Vocês escolheriam alguma delas como o número que representaria o grupo?" Apenas o Professor K se pronunciou, disse que não 
havia pensado nessa possibilidade e que, ao observar a lousa, percebia que a centena correspondente ao número 3 era mais representativa. Em contrapartida, o Professor $\mathrm{H}$ apontou que uma possibilidade seria o número 280 , pois ele representava a mediana de todos os valores, com exceção daqueles 6 números que haviam sido descartados.

Analisando as escolhas do grupo de professores, o Pesquisador 2 comentou o seguinte: "Eu observei que, mesmo [que] na segunda coleta de estimativas os dados [...] [tenham] ficado mais concentrados que na primeira coleta, o grupo optou por trabalhar com os dois conjuntos de dados." Então, o Professor A comentou que, se houvesse uma terceira coleta de estimativas, ele mudaria o valor que tinha colocado. Optamos, então, por realizar uma nova coleta de opiniões e despejamos, sob o olhar de todos os participantes, os confetes de chocolate em uma bandeja retangular de modo que todos os confeitos ficassem mais espalhados. Nesse momento, solicitamos que cada um dos participantes anotasse sua suposição. Na sequência, tais valores foram registrados na lousa, nos mesmos moldes das etapas anteriores (Quadro 5).

Quadro 5 - Registros da $3^{\text {a }}$ coleta de dados da Atividade Prática n. ${ }^{\circ} 1$

$850,130,340,290,120,256,360,718,151,290,125,240,235$

\section{Fonte: Acervo da pesquisa}

A partir disso, o grupo decidiu realizar os mesmos cálculos que haviam sido feitos para as outras coletas. Então, os valores da média e da mediana das 13 estimativas foram 315,77 e 256, respectivamente. Já os números que representavam a média e a mediana, desconsiderando os dois maiores valores (718 e 850) e o menor (120) da sequência, foram 241,7 e 248 , respectivamente. E o resultado 290 representava a moda do conjunto da coleta da terceira estimativa dos professores.

Observamos que, nessa nova coleta de dados, ao realizar os mesmos cálculos envolvendo as MTC, os palpites dos professores foram de quantidades menores de doces no recipiente. Talvez eles tenham sido influenciados tanto pela nova bandeja, que era maior que a anterior, como pelas discussões e reflexões em grupo que haviam surgido até então.

Diante de todas as sugestões de valores e modos de calculá-los, o Pesquisador 2 solicitou aos professores que apresentassem qual número representaria as estimativas do grupo e qual estratégia fora utilizada para obtê-lo. O Professor I fez a seguinte reflexão: 
No Questionário Inicial, tinha uma questão que tratou do assunto de a média obtida não ser um dos dados do conjunto. Mas não necessariamente a média será um desses valores. Como você vai somar os números e dividir pela quantidade total, é bem provável que o número encontrado não esteja na lista de valores. Então, o número 350 apareceu porque ele estava na lista, pois a gente aproximou [referindo-se a ter arredondado o valor de 343,25, correspondente à média obtida a partir das estimativas da primeira e da segunda coletas, desconsiderando-se os 6 valores discrepantes]. Agora, a dúvida ainda é 340 ou 350? Vai ser adotado um entre eles?

Contrapondo os argumentos do Professor I, o Professor G disse:

Embasados em que dados matemáticos a gente pode falar alguma coisa de números que não têm lógica nenhuma? Estimativa da turma é a análise. Se não for usado nenhum padrão, como que você vai explicar sua análise para alguém? Não pode apenas dizer: "Ah, eu tirei porque chega mais perto" ou "Ah, eu pus 0 , porque aproxima mais dele”. A Matemática não deve ser o mais precisa possivel? Tirar o número 3 e pôr o 0 fica mais distante de uma explicação. Eu acho que o mais correto é você trabalhar realmente com os números que você tem, que dai a explicação fica mais clara. Eu já não concordei de excluir alguns números. Eu acho que tinha que ser pelo menos o número 343.

Além desse posicionamento, surgiram outros, como o do Professor A, que julgou que o mais adequado seria o valor $349^{4}$, representando uma aproximação da média de todas as modas, que eram os números 180,256, 320 e 290. O Professor I, por sua vez, escolheu o valor 250, que era o arredondamento que ele atribuiu ao número 241,7 , que representava a média da coleta de dados, desconsiderando os 3 números discrepantes em relação aos demais dados da sequência. Houve também o posicionamento dos professores $\mathrm{C}$ e $\mathrm{G}$, que sugeriram o número 510, o valor aproximado da média dos 3 conjuntos de dados, sem que houvesse descartes de valores.

Em relação à proposta inicial da atividade, foi feita a contagem de votos dos participantes para cada uma das opções. Por fim, o número 316 - que era o arredondamento da média dos valores da terceira coleta de dados - foi o escolhido para representar as estimativas do grupo, o qual não ficou muito distante dos 421 confetes contidos no recipiente.

Ao término da atividade, foram feitas algumas considerações pelos mediadores, abordando aspectos então discutidos. Com relação à influência que números discrepantes exercem sobre a média, o Pesquisador 2 chamou a atenção para o seguinte conceito estatístico: "Esses valores discrepantes, na Estatística, são chamados de outliers [valores que se distanciam radicalmente dos demais]. São os valores que estão fora da estimativa.

\footnotetext{
${ }^{4}$ A média aproximada foi encontrada pelos professores a partir dos valores multimodais da $1^{\mathrm{a}}$ coleta -460 , $698,750,270,235,169,314,180,256$ e 239 e das modas da $2^{\mathrm{a}}$ e $3^{\mathrm{a}}$ coletas -320 e 290 , respectivamente.
}

ReviSeM, Ano 2021, No. 1, p. 107-123 
Todos aqui perceberam que os números 3.300 e 2.500 estavam fora. O número 73 também causou estranhamento, mas não tanto quanto os outros 2."

Aproveitando o espaço aberto para reflexão, o Professor $\mathrm{K}$ fez o seguinte questionamento: "Qual é a finalidade da mediana? Porque eu sei que é $50 \%$ para um lado e 50\% para o outro. Existe alguma situação em que a mediana é mais apropriada?". Diante disso, o Pesquisador 1 comentou que cada uma das MTC tem suas próprias características e que, de acordo com cada contexto, uma delas poderá ser a mais adequada para representar o conjunto de dados. Para exemplificar, ele apresentou a seguinte situação: "Se a gente considerar o conjunto de números formados pelos elementos 1, 2, 3, 4 e 100. Nesse caso, se eu calcular a média desse conjunto o que vai acontecer?". O Professor I respondeu que a média seria influenciada e que seu valor seria deslocado para a direita. Então, o Professor $\mathrm{K}$, além de perceber que, naquele contexto, a mediana seria a melhor opção entre as MTC para representar o conjunto de dados, reconheceu uma característica importante dessa medida: "Ah, então na mediana não precisa descartar os extremos".

Aquele momento, no qual o docente reconheceu um conceito básico da mediana, pode ser relacionado ao desenvolvimento de seu conhecimento comum do conteúdo, segundo a perspectiva de Ball, Thames e Phelps (2008). Também pode refletir um efeito positivo em seu nível de Letramento Estatístico, sobretudo no caso do elemento denominado por Gal (2004) como conhecimentos estatísticos.

A fim de ampliar o entendimento dos participantes, o Pesquisador 1 apresentou uma nova situação para que os professores percebessem a importância de analisar o contexto: "E em um caso em que os extremos se compensarem? Por exemplo, no conjunto formado pelos números 1, 49, 50, 51 e 100. Nele, os números 1 e 100 se compensam. Nesse caso, a média não sofre tanto a influência dos extremos". A partir disso, o Professor I apresentou a seguinte reflexão ao grupo, reconhecendo a importância de analisar cada caso segundo seu contexto: "Então, depende do conjunto que eu tenho". Encerrando a atividade, os pesquisadores 1 e 3 , retomaram os pressupostos envolvidos na proposta e sugeriram aos professores que situações-problema como essa poderiam ser levadas à sala de aula ao abordar tal aspecto:

Na atividade, tinha valor que era bem discrepante. O grupo percebeu que, se a gente fosse tirar aquele valor para calcular a média dos dados, pode ser que nós iríamos tirar o número que estava correto. Então, depende do contexto. Às vezes, o número pode ser discrepante e não representar nada no conjunto. Mas, às vezes, em outro contexto, aquele número pode ser bem importante para o 
conjunto de dados. (Pesquisador 1)

Quando temos somente um valor bem diferente dos demais, a média desse conjunto é influenciada. Nessa atividade, nós tínhamos combinado com o Pesquisador 2 para que ele colocasse um número bem discrepante a fim de que tal aspecto pudesse ser discutido. Então, se vocês quiserem utilizar essa atividade em sala de aula e quiserem fazer essa discussão, podem combinar isso com alguém. (Pesquisador 3)

Estudos como os de Pfannkuch e Wild (2004) identificam categorias de pensamento que consideram importantes e que são desenvolvidas quando os estudantes têm contato com problemas estatísticos contextualizados. Relatam também que, muitas vezes, em uma situação real, é necessário observar a variação dos dados e perceber a necessidade de tomar decisões por meio das quais se opte por ignorar ou não outliers ou mesmo de controlar as fontes de variação e corrigir prováveis erros de medidas. Nesse contexto, consideramos que tal reflexão pode ter sido importante para a prática docente.

Diante dessa perspectiva, o Professor E apresentou ao grupo uma experiência que tinha vivenciado durante sua prática docente, o que nos leva a inferir que conseguiu articular as reflexões promovidas a partir da atividade proposta com exemplos que podem favorecer a compreensão sobre a propriedade em questão - conhecimento especializado do conteúdo:

Eu dei um trabalho de pesquisa para meus alunos do Ensino Médio. Era uma questão que tinha que medir o peso de um determinado objeto. E um dos alunos pesou e deu um valor bem absurdo, como o número 95 da atividade. [...] Todos os alunos pesaram o mesmo objeto numa mesma balança. Então, dentro daquela pesquisa, eu tinha que retirar aquele valor para calcular a média, porque ele não estava dentro dos padrões.

Fundamentados em Zeichner (1993), acreditamos que foi importante para o grupo a criação de uma situação que favorecesse a reflexão crítica acerca de suas teorias. Consideramos que essa sessão de formação ampliou a discussão coletiva, por meio da qual puderam expor e confrontar ideias. Diante disso, percebemos que, ao término da atividade, quando alguns aspectos debatidos foram retomados, enfatizamos que, em certos conjuntos de dados, a média não é a medida mais adequada para representá-los.

Quanto à base de conhecimentos proposta por Ball, Thames e Phelps (2008), acreditamos que as discussões e reflexões ocorridas no decorrer dessa sessão favoreceram a ampliação dos conhecimentos comum e especializado dos docentes acerca das MTC. Isso pode ser observado, por exemplo: na característica de a média ser afetada por valores extremos (outliers) e não ser sempre a medida mais adequada para representar uma 
sequência de dados; no momento em que a mediana não foi afetada por valores extremos; e na ocorrência de uma distribuição amodal ou na possibilidade de haver mais de uma moda.

\section{CONSIDERAÇÕES FINAIS}

Diante das discussões e reflexões emergentes durante a realização dessa atividade, de modo geral, observamos o desenvolvimento de uma experiência significativa, segundo a concepção de Zeichner (1993), uma vez que notamos a discussão ativa dos professores. Constatamos que os argumentos apresentados pelos docentes para justificarem seus pensamentos e suas sugestões sobre os números que representariam as estimativas do grupo mostraram que a situação favoreceu essa participação ativa dos sujeitos da pesquisa, possibilitando até mesmo os direcionamentos dos mediadores para que o grupo refletisse acerca dos conhecimentos que estavam sendo discutidos e aprimorasse seu Letramento Estatístico.

Alguns pontos podem ser destacados, como a discussão proporcionada pelos valores discrepantes e o modo como eles afetam a média. Além disso, apesar de alguns professores reconhecerem e comentarem a propriedade da mediana de não ser influenciada por valores discrepantes, percebemos uma forte predileção dos docentes pela média; em contrapartida, isso não ocorreu com a mediana. Tal aspecto nos permitiu analisar as Crenças dos participantes, as quais são apontadas por Gal (2004) como concepções desenvolvidas pelas pessoas e dificilmente alteradas. Todavia, consideramos que, ao estimular a participação dos professores nas discussões e nas reflexões, pudemos favorecer possíveis mudanças em suas Crenças, mesmo que não imediatas. Acreditamos que, na sessão aqui relatada, essas mudanças se iniciaram.

\section{REFERÊNCIAS}

ALVES, T. A. S. Conhecimentos de professores de matemática da educação básica sobre o ensino de medidas de tendência central. 2016. 112f. Dissertação (Mestrado em Educação Matemática). Programa de Pós-graduação em Educação Matemática, Universidade Anhanguera de São Paulo/ UNIAN, SP, 2016.

AMORIM, M. E.; PIETROPAOLO, R. C.; GARCIA SILVA, A. da F. Formação do professor de Matemática: uma discussão sobre o ensino de probabilidade. Zetetiké, Campinas, v. 28, p. 1-14, 2020. Disponível em: https://periodicos.sbu.unicamp.br/ojs/index.php/zetetike/article/view/8657002. Acesso em: 7 nov. 2020. 
BALL, D. L.; THAMES, M. H.; PHELPS, G. Content knowledge for teaching: What makes it special? Journal of teacher education, [S. l.], v. 59, n. 5, p. 389-407, 2008.

BRASIL. Ministério da Educação. Base Nacional Comum Curricular - Educação é a Base. Brasília, DF: UNDIME/CONSED/MEC, 2018. Disponível em: http://basenacionalcomum.mec.gov.br/images/BNCC_EI_EF_110518_versaofinal_site.p df. Acesso em: 14 jun. 2020.

GAL, I. Statistical Literacy: meanings, components, responsibilities. In: BEM-ZIV, D.; GARFIELD, J. (ed.). The Challenge of Developing Statistical Literacy. Dordrecht: Kluwer Academic Publishers, p. 47-78, 2004.

GEA, M. M.; BATANERO, C.; FERNÁNDES, J.A.; ARTEAGA, P. Interpretación de resúmenes estadísticos por futuros profesores de educación secundaria. Redimat, Barcelona, v. 5, n. 2, p. 135-157, 2016.

HEALY, L.; HOYLES, C. Data Handling in the Primary Classroom: teachers and pupils as research designers. Hatfield: Advisory Unit Enterprises, 1993.

MACEDO, R. C. Conhecimentos de professores de matemática sobre o processo de ensino e de aprendizagem de noções estatísticas - curva normal. 2016. Dissertação (Mestrado em Educação Matemática) - Universidade Anhanguera de São Paulo, São Paulo, 2016.

PFANNKUCH, M.; WILD, C. Towards an understanding of statistical thinking. In BENZVI, D; GARFIELD, J (Eds.) The challenge of developing statistical literacy, reasoning, and thinking. Dordrecht, the Netherlands, Kluwer Academic Publishers, p. 1746. 2004.

RODRIGUES, B. M. B.; DA PONTE, J. P. M. Desenvolvimento do conhecimento didático de professores em Estatística: uma experiência formativa. Zetetiké, Campinas, v. 28, p. 120, $2020 . \quad$ Disponível em: https://periodicos.sbu.unicamp.br/ojs/index.php/zetetike/article/view/8656882. Acesso em: 7 nov. 2020.

SERA, E. K. Conhecimentos de professores para o ensino da leitura e construção de gráficos estatísticos na Educação Básica. 2016. Dissertação (Mestrado em Educação Matemática) - Universidade Anhanguera de São Paulo, São Paulo, 2016.

SHULMAN, L. S. Those who understand: knowledge growth in teaching. Educational Researcher, [S. l.], v. 15, n. 2, p. 4-14, 1986.

ZEICHNER, K. M. A formação reflexiva de professores: ideias e práticas. Lisboa: Educa, 1993.

ZEICHNER, K. M. Uma análise crítica sobre a "reflexão" como conceito estruturante na formação docente. Educação \& Sociedade, Campinas, v. 29, n. 103, p. 535-554, 2008.

Submetido em 13 de novembro de 2020. Aprovado em 27 de janeiro de 2021. 